\title{
Currículo, Transgressão e Diálogo: quando Outras Possibilidades se Tornam Necessárias
}

\author{
Antonio Flavio Moreira* \\ Paulo Melgaço da Silva Júnior**
}

\section{Resumo}

O século XXI tem sido caracterizado pela explosão de novas identidades políticas. Discutimos, neste texto, como a escola e o currículo vêm sendo afetados por essas mudanças. Defendemos uma apropriação das teorias tradicionais e críticas, em um trabalho estimulado pela promoção de um diálogo que favoreça novas formas de interação, de participação, de avaliação, de compreensão e de transgressão. Sugerimos que nesse processo se resgate a importância do conhecimento escolar.

Palavras-chave: currículo, transgressão, diálogo, pós-modernismo.

\footnotetext{
* Doutor em Educação pela Universidade de Londres. Professor Emérito da Universidade Federal do Rio de Janeiro (UFRJ). Professor Titular da Universidade Católica de Petrópolis (UCP). E-mail: afmcju@gmail.com ** Doutor em Educação pela Universidade Federal do Rio de Janeiro (UFRJ), professor da rede pública municipal de Duque de Caxias/Rio de Janeiro. E-mail:pmelgaco@uol.com.br
} 


\section{Curriculum, transgression and dialogue: when other possibilities become necessary}

\section{Currículum, transgresión y Diálogo: cuando otras possibilidades se hacen necesarias}

\section{Abstract}

The twenty first century has been characterized by the emergence of new political identities. In this paper we discuss how the school and the curriculum have been affected by those changes. We argue for the appropriation of traditional and critical theories in an approach stimulated by the promotion of a dialogue that favours new forms of interacction, participation, evaluation, understanding and transgression. We suggest that, in this process, the importance of school knowledge be stressed.

Key words: curriculum, transgression, dialogue, post modernism.

\section{Resumen}

El siglo XXI se está caracterizando por la aparición de identidades políticas. Debatimos en ese texto cómo la escuela y el currículum han sido afectados por ello. Estamos en favor de una apropiación de las teorías tradicionales y de las teorías críticas, en un proceso estimulado por la promoción del diálogo que incite a nuevas formas de interacción, a la participación, a la evaluación, a la comprensión y a la transgresión. Sugerimos que, a lo largo de ese proceso, se puede rescatar la importancia del conocimiento escolar.

Palabras clave: currículum, transgresión, diálogo, posmodernismo. 


\section{Introdução}

Vivemos tempos difíceis e inovadores. Novas tecnologias, novas perspectivas, novas formas de viver e conviver, novas relações com o outro, novas propostas para educar o outro. O século XXI tem trazido à tona, incessantemente, novos valores e novos paradigmas. Verdades consolidadas têm sido questionadas, transformadas, rejeitadas. Com isso, a contemporaneidade passou a englobar nova gama de pensamentos e proposições. Não se acredita mais no sujeito centrado, coerente, equilibrado, racional, construído de forma homogênea, como se considerava ser o sujeito moderno. Não se acredita mais em verdades eternas, indiscutíveis, transmitidas sem qualquer questionamento de geração a geração. Nesse conturbado panorama, diversos sujeitos sociais deixam de aceitar as posições que lhes haviam sido determinadas e passam a reivindicar fortemente novos espaços e direitos, marcando suas posições políticas pela busca de legitimação e reconhecimento de suas identidades sociais. Nesse cenário atribulado e incerto, torna-se indispensável imaginar outras possibilidades de ser, de agir, de dialogar, de viver.

Essa fase contemporânea, denominada por alguns/mas autores/as de modernidade recente (CHOULIARAKI; FAIRCLOUGH, 1999; RAMPTON, 2006), bem como de pós-modernidade ou modernidade reflexiva (GIDDENS; BECK; LASH, 1995), tem sido caracterizada pela explosão de identidades políticas centradas na ascensão do feminismo, na aceitação da diversidade sexual, na rejeição ao racismo, na migração de pessoas de antigas colônias para os países ricos. Inevitavelmente, todo esse movimento tem impactado as identidades sociais, colocando em xeque as mais tradicionais noções de masculinidade (FROSH; PHOENIX; PATTMAN, 2002) e as sociabilidades em geral.

Situamo-nos, então, em um momento histórico no qual o projeto moderno é desafiado e no qual ocorrem inúmeras mudanças no contexto sociopolítico-cultural e epistemológico. Alguns/mas autores/as classificam esse período como pós-moderno' (VEN, 2000). Segundo Moita Lopes (2008, p. 22), "são tempos em que os ideais da modernidade têm sido questionados e reescritos", afetando diretamente as formas de viver e pensar que se expressam tanto nas esferas públicas quanto nas privadas. Trata-se de momento em que se faz crucial uma grave reflexão sobre nós mesmos.

Cabe destacar, no entanto, que relações constituídas no âmbito da modernidade/ colonialidade ainda se encontram presentes em nossa sociedade atual. Assim sendo, alguns grupos buscam construir um pensamento crítico com base nas perspectivas de membros subalternizados/as na modernidade, procurando elaborar um projeto teórico centrado na crítica e na transdisciplinaridade, que se evidencie como força política contraposta às tendências acadêmicas dominantes, de construção do conhecimento histórico e social, que insistem em preservar um cunho eurocêntrico (OLIVEIRA, 2010).

Pode-se argumentar que o grande desafio hoje é, ao se produzir conhecimento, criar novas formas de inteligibilidade sobre a vida contemporânea e, ao mesmo tempo, colaborar para que se abram alternativas sociais com base nas e com as vozes que estão à margem (MOITA LOPES, 2002). Em outras palavras, trata-se de buscar maneiras de tornar diversas as "vidas vivíveis" e de tentar evitar o "sofrimento humano" (BUTLER, 2004) de identidades que foram subalternizadas ao longo dos anos, tais como: negros/as, pobres, homossexuais, indígenas, entre outras, propondo outras possibilidades de (con)viver, de viver com o outro (WALSH, 2009)

Dessa forma, se a era da razão silenciou, negou, ocultou e incluiu, no âmbito privado, várias formas e vários modos de viver, a globalização favoreceu a emergência de inúmeras transformações na vida pessoal, criando novas demandas e ansiedades. Podemos citar as questões referentes a gênero, sexualidade, masculinidade, raça, classe social. Tal fato nos leva a interrogar como essas novas demandas e polêmicas estão sendo incorporadas nos currículos e nas discussões no ambiente escolar. Que espaço está sendo oferecido para que outros conhecimentos, outras histórias de vida e outras vozes sejam reconhecidas? Neste artigo, procuraremos refletir sobre esses novos espaços e analisar como viabilizá-los no es- 
paço escolar. Inicialmente, discutiremos como a escola e o currículo vêm sendo afetados por essas mudanças.

\section{Currículo e escola}

Os cotidianos de nossas escolas evidenciam os contraditórios efeitos de toda essa agitação social. A cada dia, presenciamos lutas de movimentos e grupos sociais para que os anseios e as necessidades de seus membros sejam discutidos na escola ${ }^{2}$ e no currículo. Se entendermos o currículo como o coração da escola, podemos afirmar que por seu intermédio se apresentam aos alunos a visão de mundo que se quer difundir e a ideologia que se pretende inculcar. Pinar (2004) afirma que o currículo escolar incorpora o que escolhemos relembrar sobre o passado, o que acreditamos sobre o presente e o que esperamos do futuro.

O currículo envolve, assim, os espaços/tempos em que os sujeitos interagem, as ações escolares e culturais se desenvolvem e renovadas tecnologias são empregadas. Nesse contexto, se ensina e regula o corpo, produzindo subjetividades e arquitetando formas e possibilidades de viver em sociedade. O currículo é o espaço escolar onde se concentram e se desdobram lutas que ocorrem no seio da sociedade, em torno de diferentes significados sobre o social e o político.

Conforme Apple (1992), “o currículo nunca é apenas um conjunto neutro de conhecimentos [...]. É produto das tensões, conflitos e concessões culturais, políticas e econômicas que organizam e desorganizam um povo" (p. 59). Reforça-se, portanto, a idéia de que, ao privilegiar uma determinada concepção de currículo, a escola opta por certa forma de produção do conhecimento e, por conseguinte, por determinado processo de construção de identidade. Para Silva (1999), "o currículo estabelece diferenças, constrói hierarquias e produz identidades" (p. 12).

É por meio do currículo, concebido como elemento nuclear da política educacional, que os distintos grupos sociais - especialmente os dominantes - expressam sua visão de mundo, seu projeto social e suas "verdades". Sendo assim, problematizar e questionar o currículo pode constituir um caminho inicial no esforço por formar novas subjetividades que não aceitem as normas opressoras.

Como a difusão de novas identidades culturais demonstra que a cultura, longe de ser homogênea e monolítica, é de fato, complexa, múltipla, conflituosa, descontínua, o currículo pode expressar todo um deslocamento de fronteiras, bem como questionar as diferenças de gênero, raça e sexualidade. Nessa perspectiva, visões hegemônicas terminam por ser problematizadas. O currículo é, assim, um campo de lutas e de produtividade, diretamente relacionado à cultura e às relações sociais.

Na contemporaneidade em que nos situamos, o pensamento pedagógico deixa-se afetar por uma série de teorizações curriculares denominadas de pós-críticas, presentes no campo curricular de nosso país desde 1990 e que se tornaram dominantes desde os anos 2000. Nesse conjunto de teorias encontram-se os estudos pós-estruturais, pós-coloniais, pós-modernos, pós-fundacionais e pós-marxistas. Cada um desses grupos apresenta questões e problemáticas próprias para o campo da educação e do currículo. Sem pretender discutir tais teorizações, queremos destacar o fato de que teorizações tradicionais de currículo, juntamente com as críticas e as pós-críticas, estão presentes nos contextos escolares, contribuindo para a permanência de determinadas visões de mundo e de sociedade.

Cabe interrogar se essas teorizações conseguem atender às reais necessidades advindas das lutas dos novos grupos sociais que buscam reconhecimento e legitimação. Será possível defender a descolonização dos currículos por meio de um dialogo entre as diversas teorizações? A fim de examinar essa perspectiva, analisamos a viabilidade de um diálogo que contribua para essa descolonização.

\section{Possibilidades de transgressão: quando ousar é preciso}

Hooks (1994), em sua obra Teaching to transgress, chama a atenção para a necessidade de se quebrarem pa- 
radigmas, de se imaginarem novas possibilidades pedagógicas, de se trazerem novas histórias e novos sujeitos para o contexto das salas de aula. A autora defende a importância de se transgredir. de se buscarem possibilidades de construção de novas realidades.

Segundo Pennycook (2006, p. 74), transgredir é "pensar o que não deveria ser pensado, fazer o que não deveria ser feito". Para Hooks (1994), transgredir é mover-se para além das fronteiras, é reconhecer e desafiar as limitações, é buscar conhecer o que está além do que é permitido. A autora acentua a importância da transgressão docente, que implica acompanhar alunos e alunas no cruzamento de fronteiras. Assim, ao se lançar mão de diferentes paradigmas (DENZIN; LINCOLN, 2006) para trabalhar com a mestiçagem e propor um diálogo entre as duas teorias, procura-se arriscar, descobrir e trilhar novos caminhos. É nesse sentido que se vislumbram novas possibilidades para trabalhar e analisar as diversas questões que emergem no campo do currículo - questões de sexualidade, raça, família, gênero, masculinidades e classe social.

Nessa perspectiva, a interseção dessas linhas de pensamento pode contribuir para ampliar o arcabouço de conhecimentos e sugerir novas possibilidades de um meIhor conviver e de evitar sofrimento para diversas vidas humanas. Na tentativa de desenvolver o diálogo que se faz necessário, se buscam caminhos que permitam renovar a prática pedagógica nas escolas, que recebem sujeitos diferentes, com diferentes subjetividades.

Consideramos que a prática curricular constitui um espaço privilegiado em que se pode formular um projeto para a construção da autonomia com base em princípios pós-modernos. Assim, defendemos uma apropriação crítica das duas teorias, em um trabalho intelectual que se utilize da intersecção entre a autonomia e o pós-modernismo: um projeto educativo que valorize o processo de construção da autonomia em uma perspectiva neomarxista. Esse projeto "continua útil, tanto por propiciar uma compreensão mais aguda da sociedade e da escola capitalistas, como por conclamar a cumplicidade na proposição de novas alternativas" (MOREIRA, 2010, p. 108).
Tal projeto necessita considerar as histórias locais e abrir espaço para as pequenas narrativas, desafiando concepções de verdade e explicações produzidas pelas grandes narrativas.

Acreditamos que as correntes pós-modernas possam "oferecer um potencial para questionamentos radicais das concepções pedagógicas tradicionais e para a formulação de propostas curriculares pautadas pela intenção de resistir ao status quo" (MOREIRA, 2010, p.108). Para isso, há que se promover as conexões entre os sistemas macro e micro de forma articulada.

Buscando compreender como favorecer o diálogo entre essas teorias, recorremos a Pennycook (2006), procurando empregar simultaneamente os arcabouços teóricos de Fanon e Foucault para analisar os dois lados da questão. A aplicação dessas duas lógicas (desessencialização e promoção da autonomia) pode contribuir para a abertura de novas possibilidades de configuração das práticas curriculares.

O que estamos sugerindo é que se opere com a estrutura crítica de Franz Fanon e com o ceticismo epistemológico de Michael Foucault. Ou seja, por um lado, com a urgência e as realidades do embate político; por outro, com a necessidade de sempre questionarmos nossas pressuposições e as dos outros.

Trata-se de observar como as diferentes subjetividades estão interligadas. Desejamos ir além da ideia iluminista de salvação do sujeito, mas sem pretender deixar o mundo como está, sem intervenções de outros nas formas de pensar (BAUMAN, 2003).

Cientes da relevância da escola, sustentamos que uma das nossas responsabilidades é tentar formar subjetividades rebeldes (SOUSA SANTOS, 1996), que não se conformem com normas capazes de subalternizá-las e que busquem novas formas de reinventar a vida social. Para tanto, esse projeto de emancipação deve dar voz aos diversos grupos sociais silenciados e reprimidos ao longo dos anos, sem hierarquizá-los. Com base em Moita Lopes (2006, p. 96), acreditamos que "há várias emancipações 
sociais fundamentadas na ética e na politização da vida social". Outras possibilidades, então, precisam ser incentivadas e desenvolvidas.

\section{Alternativas no campo}

Novamente recorremos a Pennycook (2006) para reforçarmos os níveis de tensão no trabalho com as duas teorizações e nos beneficiarmos do recurso a Fanon e Foucault, na defesa da importância de um processo de ensino engajado em práticas problematizadoras.

Por um lado, dentro dos imperativos de lidar com o mundo real dos embates, há demandas em competição por um foco na dominação/no controle (efeitos contingentes e contextuais do poder), na disparidade (desigualdade e necessidade de acesso), na diferença (comprometimento com a diversidade) e no desejo (compreendendo como identidade e agenciamento/ ação estão relacionados). Por outro lado, reconhecendo o imperativo foucaultiano de sempre interrogar os próprios modos de pensar, de manter um ceticismo constante em relação aos conceitos e modos dos pensar. (PENNYCOOK. 2006, p. 82-3).

Com isso, apropriamo-nos das palavras de Fabrício (2006, p. 49), cientes "de que nossas práticas discursivas envolvem escolhas que têm impactos diferenciados no mundo social e nele interferem de formas variadas". Propomos a criação de uma agenda de trabalho, na qual se incluam as duas teorizações. Em sala de aula, sugerimos o desenvolvimento de uma agenda política, transformadora/intervencionista e ética, fundamentada em objetivos do trabalho pedagógico, tais como:

- reconhecer, problematizar, estranhar e desestabilizar: a proposta é interrogar os discursos essencializados e naturalizados que circulam na sociedade e que tanto causam discriminação, sofrimento e dor às pessoas; mostrar como esses discursos promovem a desigualdade e a hierarquização;

- valorizar as diferenças e reconhecer a igualdade de direito a uma educação de qualidade: é relevante reconhecer as diversas identidades culturais e buscar promover o diálogo entre elas, em prol da valorização das mesmas, sem hierarquizações; refletir sobre a diferença colonial e buscar construir novas conexões, objetivando uma educação para a vida; destacar a importância da luta pelo direito à igualdade no processo de reconhecimento e valorização das identidades;

- resgatar identidades e saberes: considerar sempre as identidades individuais, coletivas e institucionais, expressas nas histórias de vidas, nos saberes ancestrais, nos processos de hibridização cultural, como movimento dinâmico que se relaciona com o local e o global. Trata-se de produzir novas interações e questionar os conceitos de universal e de centro;

- rever as relações centro/periferias: avaliar o que a periferia pode ensinar ao centro;

- aprender, reaprender, transgredir: com os olhos do subalterno, buscar desenvolver uma nova lógica e analisar que conhecimentos são centrais para a construção e a compreensão da realidade. Resgatar saberes excluídos, silenciados e subalternizados no processo de colonização. Trata-se de pluriversalizar o conhecimento e de articular saberes, ou seja, de abrir a sala de aula e a escola para múltiplos saberes, sem hierarquizá-los (MIGNOLO, 2003).

- construir novas possibilidades de ação: avaliar e ressignificar as práticas escolares; questionar a educação e sociedade atuais e discutir como viver no futuro (em que tipo de sociedade), como conviver com o outro e com a natureza;

- valorizar a autodeterminação: acentuar que as comunidades e os povos subalternizados são capazes de elaborar e defender projetos de reconstrução social.

Argumentamos que o desenvolvimento dessa agenda pode ser estimulado pela promoção, entre atores e entre teorias, de um diálogo que favoreça novas formas de interação, de participação, de avaliação e de compreensão.

\section{Favorecendo o diálogo}

Vale retomar a perspectiva, por nós reiterada em outros momentos, de se promover, no currículo, o diálogo entre as diferenças. Pode-se partir do princípio de que toda identidade é construída por meio da diferença, o que nos demanda o esforço de começarmos a viver com a política da diferença. Mas a aceitação de que a identidade é uma 
construção, uma ficção, também requer seu oposto - o fechamento necessário para criar comunidades de identificação (nação, família, grupo étnico). Formas de ação política (partidos, movimentos, classes) são também fechamentos temporários, arbitrários e parciais. Não é possível existir identidade no mundo sem um fechamento arbitrário, sem o fim da sentença. $O$ discurso é sem fim. Mas, para dizer algo em particular, é preciso parar de falar. Esses fechamentos arbitrários, não terminados, podem ser chamados de eu, sociedade, política (HALL, 1997).

Ao mesmo tempo, reconhecer a diferença, a impossibilidade de uma identidade "unificada", não pode significar uma política da dispersão infinita (ou seja, uma política de nenhuma ação). É possível pensar em fechamentos contingentes, é possível supor o não fechamento de uma identidade a outras (apesar da diferença), é possível, portanto, defender o diálogo.

Especificamente preocupados com o diálogo nas escolas, Carlson e Apple (2000) sugerem que as concebamos como:

\footnotetext{
"espaços públicos", onde diferentes grupos da comunidade podem reunir-se para dialogar, tanto para clarear suas diferenças quanto para trabalhar no sentido de alguns entendimentos e acordos em relação ao significado de eqüidade, liberdade, comunidade e outros construtos democráticos em situações concretas. (Carlson; Apple, 2000. p. 34).
}

Objeto da preocupação de diferentes autores (Burbules, 1993; Ellsworth, 1997), o diálogo corresponde ao objetivo nuclear da teoria da tradução, tal como formulada por Sousa Santos (1995, 1997, 2005). A ela recorremos para refletir sobre o diálogo na escola e no currículo.

Para Sousa Santos, embora superáveis, há inegáveis problemas no diálogo entre as diferenças. $\mathrm{O}$ autor sustenta que diferença sem inteligibilidade conduz à incomensurabilidade e, em última instância, à indiferença. Sugere que as diferenças dialoguem entre si, se articulem. Ressalta a necessidade de diálogos transculturais, norteados pela visão de que todas as culturas têm concepções de dignidade humana, ainda que distintas.
Acrescenta: todas as culturas são incompletas e problemáticas em suas noções de dignidade humana. As versões diferem, conseqüentemente, sendo umas mais amplas e abertas que outras.

O autor defende a possibilidade de uma tradução, que permita criar inteligibilidade recíproca entre as experiências do mundo, tanto as disponíveis como as possíveis, sem pôr em risco suas identidade e autonomia, ou seja, sem as reduzir a identidades homogêneas. Para Sousa Santos (2005), os movimentos sociais e as ONGs constituem-se em torno de objetivos mais ou menos confinados, criam suas próprias formas e estilos de resistência, especializando-se em tipos de práticas e de discursos que os distinguem de outros movimentos e organizações. A identidade se cria com base no que os separa dos demais. Daí podem resultar fragmentação e atomização, que são o lado negativo da diversidade e da multiplicidade.

Cabe, então, promover articulações de práticas e de saberes com foco no que une, não no que separa. Faz-se necessário um significativo esforço de tradução, que favoreça inteligibilidade recíproca sem destruir as identidades dos que nela estejam envolvidos. Através do trabalho de tradução, a diversidade é celebrada como uma condição de partilha e de solidariedade (SOUSA SANTOS, 2005).

Como favorecer, de fato, a tradução de saberes e de práticas? Como promover o debate e o diálogo entre diferentes visões de mundo e de direitos humanos? Como desenvolver um diálogo intercultural? Como promover a tradução sem ameaçar o que se faz específico das identidades envolvidas? Será viável o exercício da tradução na política e na prática curricular? Estaremos dispostos a promover, na escola, inteligibilidade, coerência e articulações? Estaremos dispostos a rever a posição usualmente concedida aos saberes e valores hegemônicos? Que se deve traduzir, como, quando e por quê?

Para Sousa Santos, não sabemos se um mundo melhor é possível, nem mesmo se é concebido da mesma maneira pelos que o defendem. Em suas palavras: 
o objetivo do trabalho de tradução é estimular, entre os movimentos sociais e organizações progressistas, a vontade de criarem em conjunto saberes e práticas suficientemente fortes para fornecer alternativas credíveis à globalização neoliberal, a qual não é mais do que um novo passo do capitalismo global no sentido de subordinar totalmente a riqueza inesgotável do mundo à lógica mercantil. (...) A possibilidade de um futuro melhor não está, assim, num futuro distante, mas na reinvenção do presente, (...) tornado coerente pelo trabalho de tradução. (Sousa Santos, 2005, p. 133).

Para que o currículo possa corresponder a um espaço de estímulo à tradução, precisa tornar-se também um espaço de construção e reconstrução de conhecimentos. Para isso, os professores precisam assumir uma postura investigativa que lhes favoreça analisar suas práticas e entender os problemas envolvidos na exclusão de alguns estudantes da escola, compreendendo melhor as vidas, os saberes, os valores e as culturas desses alunos.

Ao compreenderem melhor esses alunos, os docentes podem propiciar novas formas de interação, melhor lidando com as inevitáveis tensões que se tecem nas relações com as crianças e os adolescentes reais de suas salas de aula. Podem avaliar as atividades didáticas e redimensioná-las pelo olhar da infância, da adolescência, da juventude, contribuindo para currículos mais significativos para seus alunos concretos. Ao procurarem conhecer o outro é importante levar em conta que ele é dinâmico, sempre nos apresenta novas e inesperadas características e facetas. A identidade constitui, assim, um processo, reformula-se constantemente. Acresça-se o fato de que não há identidade mestra que consiga dar conta das idiossincrasias dos membros que compõem um dado grupo. Ou seja, quem ensina precisa estar sempre aprendendo e reaprendendo quem é o aluno a quem precisa ensinar. Precisa estar sempre refletindo sobre sua sala de aula e sua prática.

Ainda buscando consolidar a escola como espaço de construção e reconstrução de conhecimentos, sugerimos que se resgate a importância do conhecimento escolar. Reconhecemos que o foco na criança, em seu desenvolvimento, seus interesses, suas experiências e suas habilidades, favoreceu inegáveis avanços no desenvolvimento de currículos. Sugerimos, contudo, que ao foco na criança se associe uma significativa preocupação com o conhecimento, com uma instrução ativa e efetiva, com um professor ativo e efetivo que bem conhece e ensina determinados conteúdos curriculares. Não basta elevar a auto-estima do aluno que esteja sendo subjugado. Não basta oferecer-lhe um espaço em que possa conviver e socializar-se. Não basta procurar favorecer a construção de identidades que caminhem na contramão dos padrões hegemônicos. Não basta tornar a escola agradável, acolhedora e receptiva a diferentes manifestações culturais.

Nos currículos, argumentamos, há que se evitar guetos, restritos aos artefatos culturais familiares ao aluno Há que se evitar que se passe da valorização de padrões hegemônicos para a celebração de padrões minoritários. Trata-se de garantir ao aluno o direito de escolher sua identidade. Trata-se de impedir que o estado ou a tribo acabe por retirar do estudante essa liberdade de escolha e essa responsabilidade. Trata-se de alargar horizontes, oferecer perspectivas.

Para que a liberdade se exerça, a escola precisa ampliar-se, abrir-se, aumentar as oportunidades de acesso às ciências, às artes, a novos saberes, a novas linguagens, a novas interações, a outras lógicas, à capacidade de buscar conhecimentos, ao aprofundamento, à sistematização e ao rigor. Precisa considerar o aluno em suas diferentes dimensões sem, contudo, secundarizar o intelecto e a aprendizagem. O que estamos defendendo, em síntese, é que o conhecimento escolar seja visto como um útil instrumento para o desenvolvimento da autonomia de nosso estudante.

\section{Notas}

10 termo pós-moderno é muito amplo. O pós-modernismo apresenta uma reação aos ideais de saber do pensamento moderno, questionando o sujeito livre, autônomo, centrado e soberano da modernidade. Já o pós-estruturalismo, de acordo com Silva (1999), busca teorizar sobre a linguagem e o processo de significação. Aqui, o sujeito é uma invenção cultural, social e histórica, não possuindo uma essência. Por sua vez, os pós-coloniais procuram analisar as diferentes relações de poder entre as nações a partir da herança da conquista colonial europeia. Temos ainda os denominados decoloniais, que surgem na América La- 
tina, e se propõem a pensar esse processo de colonização a partir do olhar do colonizado.

2 Estas lutas estão sendo incorporadas em leis como LDB 9394/96, Parâmetros Curriculares Nacionais, Leis 10.639/03 e 11.645/08125, que recomendam o ensino da cultura e da história afro-brasileira e indígena . Acirradas disputas envolvem o esforço para que questões de gênero e sexualidades consigam seus espaços nas escolas.

\section{Referências}

APPLE, M. A política do conhecimento oficial: faz sentido a ideia de um currículo nacional? In: MOREIRA, Antônio Flávio Barbosa; SILVA, Tomaz Tadeu (Orgs.). Currículo, cultura e sociedade. São Paulo: Cortez, 1992.

BAUMAN, Z. A sociedade líquida. Folha de S. Paulo, São Paulo, 19 out. 2003. Caderno Mais! p. 5-9.

BRASIL. Lei 9.394/96. Lei de Diretrizes e Bases da Educação Nacional (Lei 9.394/96). Diário Oficial da União, 13 de julho de 1996.

. Lei 10.639, de 9 de janeiro de 2003. Diário Oficial da União, 10 de janeiro de 2003. Altera a Lei no 9.394, de 20 dez. 1996, que estabelece as diretrizes e bases da educação nacional, para incluir no currículo oficial da Rede de Ensino a obrigatoriedade da temática "História e Cultura Afro-Brasileira".

Lei 11.645 de 10 de março de 2008. Diário Oficial da União, 11 de março de 2008. Altera a Lei no. 9.394, de 20 dez. 1996, modificada pela Lei 10.639, de 9 jan. 2003, que estabelece as diretrizes e bases da educação nacional, para incluir no currículo oficial da Rede de Ensino a temática "História e Cultura Afro-Brasileira e Indígena".

Secretaria de Educação Fundamental. Parâmetros curriculares: terceiro e quarto ciclos: apresentação dos temas transversais. Brasília: MEC/SEF, 1998

BURBULES, N. C. Dialogue in teaching: theory and practice. New York: Teachers College Press, 1993.

BUTLER, J. Undoing gender. New York: Routledge, 2004.

CARLSON, D.; APPLE, M. Teoria educacional crítica em tempos incertos. In: HYPOLITO, A.; GANDIN, L. (Orgs.). Educação em tempos de incertezas. Belo Horizonte: Autêntica, 2000.

CHOULIARAKI, L.; FAIRCLOUGH, N. Discourse in late modernity. Edinburgh: Edinburgh University Press, 1999.

DENZIN, N. K.; LINCOLN, Y. S. O planejamento da pesquisa qualitativa: teorias e abordagens. 2. ed. Porto Alegre: Artmed, 2006.

ELLSWORTH, E. Teaching positions: difference, pedagogy, and the power of address. New York: Teachers College Press, 1997.

FABRÍCIO, B. F. Linguística aplicada como espaço de desaprendizagem: redescrições em curso. In: MOITA LOPES, L. P. (Org.).
Por uma linguística aplicada indisciplinar. São Paulo: Parábola. 2006.

FRASER, N. Da redistribuição ao reconhecimento? Dilemas da justiça na era pós-socialista. In: SOUZA, J. (Org.). Democracia hoje. Brasília: UNb, 2002.

FROSH, S.; PHOENIX, A.; PATTMAN, R. Young masculinities: understanding boys in contemporary society. New York: Palgrave, 2002.

GIDDENS, A.; BECK, U.; LASH, S. Modernização reflexiva. São Paulo: Editora Unesp, 1995.

HALL, S. A centralidade da cultura: notas sobre as revoluções culturais do nosso tempo. Educação e Realidade, Porto Alegre, v. 22, n. 2, p. 15-46, jul./dez. 1997.

HOOKS, B. Teaching to transgress: education as the practice of freedom. New York: Routledge, 1994.

MIGNOLO, W. Histórias globais / projetos locais: colonialidade, saberes subalternos e pensamento liminar. Belo Horizonte: Editora UFMG, 2003.

MOITA LOPES, L. P. Identidades fragmentadas: a construção discursiva de raça, gênero e sexualidade em sala de aula. Campina: Mercado das Letras, 2002

Linguística aplicada e vida contemporânea: problematização dos construtos que tem orientado a pesquisa. In: (Org.). Por uma linguística aplicada indisciplinar. São Paulo: Parábola Editorial, 2006.

Sexualidades em sala de aula: discurso, desejo e teoria queer. In: CANDAU, V. M.; MOREIRA, A. F. (Org.) Multiculturalismo: diferenças culturais e práticas pedagógicas. Petrópolis: Vozes, 2008

MOREIRA, A. F. A configuração atual dos estudos curriculares: a crise da teoria crítica. In: PARAISO, M. A (Org.). Antonio Flavio Barbosa Moreira: pesquisador em currículo. Belo Horizonte: Autêntica, 2010. (Coleção Perfis da Educação, 2).

OLIVEIRA, L. F. Histórias da África e dos africanos na escola: as perspectivas para a formação dos professores de história quando a diferença se torna obrigatoriedade curricular. 2010. Tese (Doutorado em Educação) - Pontifícia Universidade Católica do Rio de Janeiro - PUC-Rio, 2010.

PINAR, W.F. What is curriculum theory? Mahwah, NJ: Erlbaum, 2004

PENNYCOOK, A. Uma linguística aplicada transgressiva. In: MOITA LOPES, L. P (Org). Por uma linguística aplicada indisciplinar. São Paulo: Parábola, 2006.

RAMPTON, B. Continuidade e mudança nas visões de sociedade em linguística aplicada. In: LOPES, L. P. (Org.). Por uma linguística aplicada indisciplinar. São Paulo: Parábola, 2006. 
SILVA JUNIOR, P. M.; MOREIRA, A. F. Periferias, sexualidades e educação para a sexualidade: desafios para as práticas curriculares. In: SOBREIRA, H. G. (Org.). Educação, cultura e comunicação nas periferias urbanas. Rio de Janeiro: Lamparina, Faperj, 2010.

SILVA, T.T. Documentos de identidade: uma introdução às teorias do currículo. Belo Horizonte: Autêntica, 1999.

SOUSA SANTOS, B. O fórum social mundial: manual de uso. São Paulo: Cortez, 2005.

SOUSA SANTOS, B. S. Para uma pedagogia do conflito. In: SILVA, L. H.; AZEVEDO J. C.; SANTOS, E. S. (Orgs.). Novos mapas culturais, novas perspectivas educacionais. Porto Alegre: Sulina, 1996.

SOUSA SANTOS, B. Toward a multicultural conception of human rights. Zeitschrift für Rechtssoziologie, n. 18, p. 1-14, 1997.

SOUSA SANTOS, B. Pela mão de Alice: o social e o político na pós-modernidade, São Paulo: Cortez, 1995.

VENN, C. Occidentalism: modernity and subjectivity. London: Sage, 2000.

WALSH, C. Interculturalidad y (de)colonialidad: perspectivas críticas Y políticas. Conferência inaugural. XII Congresso ARIC, Florianópolis, Brasil, 29 jun. 2009.

Recebido em 16 de janeiro de 2016.

Aceito em 25 de fevereiro de 2016. 